\title{
The Influence of Travel Expectation Theory on RV Travel Consumption Decision
}

\author{
Yang Xuefeng ${ }^{1, *}$, Gao Zhenggang ${ }^{1}, \mathrm{Ma} \mathrm{Li}^{1}$,Wang Qiang ${ }^{1}$,Liu Xusheng ${ }^{1}$, Xu Shuo ${ }^{1}$ \\ ${ }^{1}$ Ordos Institute of Technology, Ordos, Inner Mongolia, China
}

\begin{abstract}
With the improvement of people's quality of life, driven by consumer demand such as "self-drive tour" and "RV travel", the RV market in China is growing rapidly. The development of RV camp service is related to the satisfaction and development degree of RV travel. Based on expectancy theory, this paper uses the questionnaire survey in Inner Mongolia ordos RV tourism development. For tourists on the tourism products, tourism facilities, tourism environment, tourism publicity tourist expectation theory analysis, consumers' motivation of RV travel under the influence of tourism expectations and titer, SPSS statistical methods are used to find the main factors of RV camp consumption decisions. Finally, improvement strategy is put forward to improve the tourism infrastructure, tourist convenience and satisfaction, promoting the development of ordos RV tourism.
\end{abstract}

\section{Page layout}

In recent years, driven by consumer demand such as "selfdriving travel" and "RV travel", China's RV market has grown rapidly. According to the statistics released by the Association of RV, the sales volume of RV reached 9004 units in the first three quarters of 2020, with a year-on-year growth of $49 \%$ and the market size exceeding 6 billion yuan. China's RV market continues to grow rapidly, the industry situation is good, and RV sales boom at the same time. RV camps are also gradually developed. Up to now, more than 2000 national RV camp have been open to the public.

Auto camping originated in the United States in 1860. It was originally an autocamping activity to organize young people to temper their will and strengthen their bodies. In 1910, the predecessor of "American Camping Association", "American Campground Managers Association", was founded, and as a new industry, autocamping was born in western countries [1]. China Camping Association was founded in Beijing in 2004, and in 2006, it built Beijing's first self-driving camping demonstration camp. Compared with developed countries, China's RV campsites show the following characteristics: in 2017, the United States has about 27,000 campsites, the European area has 25,000 campsites, the number of campsites in China in 2017 is less than 800, far below the international average; Moreover, China has not yet formed a unified standard for camping sites, so it is urgent to improve the standardization and standardization of RV camping sites. Restricted by national conditions and tourism policies, the RV camp has a low level of overall development. The service level of RV camp is uneven, and customer satisfaction has a great influence on the publicity of the camp [2-3].
In 2014, Premier Li Keqiang of the State Council clearly proposed to "upgrade tourism and leisure consumption and build self-driving and RV camps".2016 is the first year of the national "13th Five-Year Plan", the development of tourism as the "13th Five-Year Plan" national key special plan, the focus of its development is the planning and construction of RV camping ground.All parts of the country are actively responding to the national policy, and combining with their own actual situation to make the development of camping site rules and strategies. Inner Mongolia, as an important area of China's grassland and desert tourism, has established or planned 128 selfdriving RV camping sites and more than 3727 self-driving RV camps except Manzhouli.By 2020, it would basically build a tourism and leisure resort base that reflects grassland culture and unique northern Chinese characteristics. Take ordos as an example, it has built Kangbashi of Lu You RV lighting star RV camp, ovens in snow and ice paradise camp, relying on the grassland scenery road in Tujunudeleqing campsite, relying on the desert and establish HaoLang RV camp, ordos Abuhai gully grassland RV camping site, town in ordos racing cars drive sports camp, the town car drive car racing camp in August 2019 in the sixth China vehicle (RV) camping conference "Five-star car drive sports camp" title.

After 2018, the construction of "Chinese-style" campsites has gradually entered a more detailed stage. Major RV campsites have started to study how to improve the occupancy rate of the campsites on weekdays, how to expand the flow on weekends, how to attract different types of tourists and how to provide high-quality services for tourists. In fact, the main core is how to do a good job in the operation of the camp, and in this process will produce a lot of camp development models. This requires continuous innovation in the construction and operation of 
the camp to create a truly localized development model. Only in this way can the camp stand out [4-6]. Based on the theory of tourism expectation, this paper focuses on the investigation and research of consumer experience and behavior of RV campsites, so as to obtain the relevant content that consumers pay the most attention to, and provide development suggestions for the construction of RV campsites.

\section{Application of tourism expectation theory in RV tourism}

Expectancy Theory was put forward by Victor Frum, a famous North American psychologist and behavioral scientist, in his work and motivation in $1964^{[7]}$.

Expectancy Theory, also known as "valence-means expectation theory", the relationship between the need and the goal is expressed by the formula: incentive force $=$ expected value $\times$ valence. Yue Xianfeng, Henan normal university in the expectancy theory of tourism impact on sports tourism consumption motives ", according to the theory of frum and tourists travel behavior decisionmaking, will expect theory application for tourism theory, the expression of the public into $T M=T E \times T V$, that is, tourism motivation is tourism titer and the desired product, can use tourism expectations and titer to find travel incentives to make travel decisions, to explore the influence of the sports tourism consumption motivation, it is better to practice, this article will use the expectation theory to explore the RV tourism travel motivation [8].

In this formula, the power of excitement refers to the intensity of mobilizing the initiative of the individual and arousing the internal potential of the person; Expectation is based on personal experience to judge the degree of grasp of the goal; Valence is the value of an attainable goal for satisfying an individual's needs. According to the theory of tourism expectation, tourists' travel motivation consists of three processes. First, tourists combine themselves with the outside world to form travel expectation. Second, according to all kinds of information on the RV tourism or RV camp terrain effectiveness price, that is, to give a self-evaluation; Finally, tourism incentives are formed according to tourism expectation and tourism valence, so as to make tourism decisions, such as whether to carry out RV tourism, how to carry out RV tourism and which RV camp to choose [9-11].

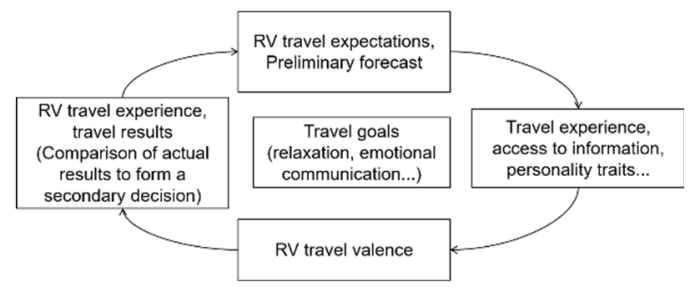

Fig. 1. Steps of Expectation Theory Implementation.

According to Froom, what is expected is not equal to reality, and there are generally three possibilities between expectation and reality: expectation is less than reality, expectation is greater than reality, and expectation is equal to reality. These three situations have different effects on people's enthusiasm. In RV tourism, we can understand it as the size of self-needs realized by RV travel.

\section{Investigation of RV travel intention based on travel expectation theory}

This survey was conducted by questionnaire and random completion via the Internet. The survey was conducted from January 28, 2021 to February 2, 2021, and 217 valid questionnaires were collected. The basic information of the survey is as follows: the majority of respondents were from Dongsheng, Kangbashi, Yijinhuoluo and Dalat ; The sex ratio is 110:107, and the sex distribution is reasonable. Age was found in all stages, with 91 samples aged from 31 to 40 accounting for the largest proportion. There are all levels of education, and the maximum proportion of bachelor's degree is 54.8\%. The occupational distribution was mainly in public institutions (44). The monthly income is basically concentrated within 12000 yuan, and the monthly income between 5000 and 8000 yuan is in the majority; The proportion of families with parents and children reached $64.5 \%$. Through the questionnaire, it is concluded that the RV tourism decision-making has the following characteristics:

\subsection{Tourism information is mainly derived from the Internet}

According to the questionnaire results show that the main information through the Internet to learn about $63.6 \%$ of people travel, at the same time the part of consumers said they will be according to the review site on the camp of the score in the judgement and evaluation data, some consumers said they from trill, weibo see others travel to RV travel inspired his interest.

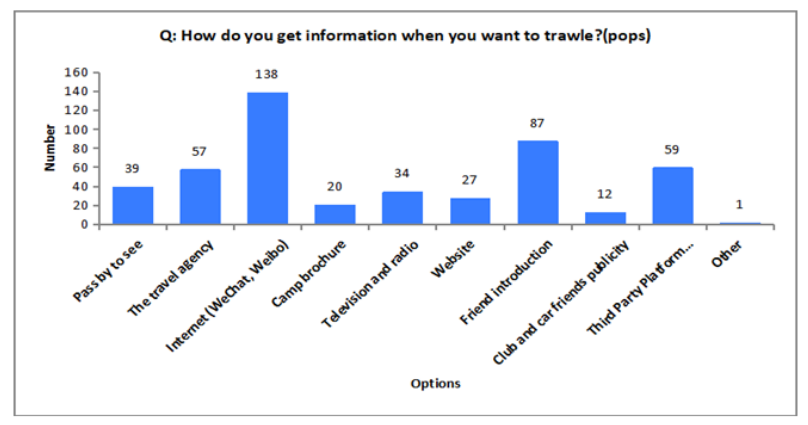

Fig. 2. Travel information to understand channels.

\subsection{Factors influencing camp selection}

In terms of the purposes of travel, the main purposes are "exercise, regulate body and mind, keep in good health", "accompany family, deepen emotion", "stay away from the city, get close to nature", and "release the pressure of life and work". The types and characteristics of the surrounding scenic spots were very important to the selection of the camp area, accounting for $69.7 \%$. In terms of catering, Chinese food, special food and buffet accounted for $90 \%$ of the total. $90 \%$ of consumers are willing to participate in the camp's entertainment 
programs; In the camp entertainment projects, sports, recuperation, science and technology and entertainment accounted for the largest proportion, through these entertainment projects can achieve the purpose of relaxing body and mind, relieve pressure, get close to nature and accompany family; RV campsites attract more consumers, among which, experience the unique leisure way of the campsite and try the unique accommodation of the campsite account for the largest proportion, $67.1 \%$ and $51.0 \%$ respectively. In terms of the knowledge of emergency measures in the RV camp, $54.19 \%$ people basically have no knowledge of this aspect.

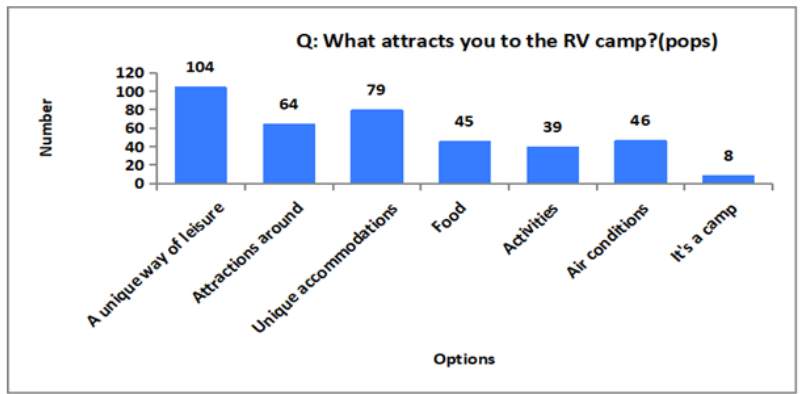

Fig. 3. The attraction of RV campsites to consumers.

\subsection{Family and parent-child short-term travel}

In addition to the teachers and students can take advantage of the summer and winter vacation travel, on weekends and golden weeks, the number of proportion is the largest, expect to stay in the camp to select two days accounted for $39.5 \%$, maximum travel in the organizational structure of family travel accounted for $75.58 \%$, according to statistics, in 2020, although affected by the epidemic holidaying market recovery degree of substantial quality improvement is quite obvious, visible short-term close family parent-child travel has become the best choice for celebrate the weekend.

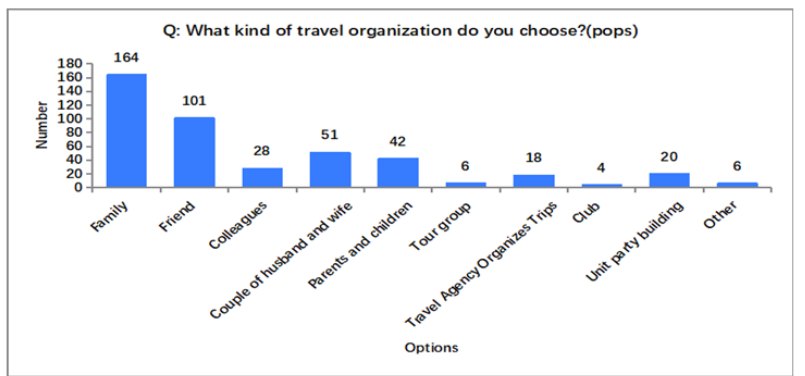

Fig. 4. Caption of the Figure 1. Below the figure.

\subsection{RV tourism in Ordos is in its primary stage and has a large space for development}

In the question "Do you think the popularity and development degree of RV tourism in Ordos ", 156 people choose the early development stage, accounting for $71.9 \%$; Combined with the fact that Ordos is a tourist city, there are less than $10 \mathrm{RV}$ camps under construction at present, and the number of people who have the intention of RV tourism accounts for $71.4 \%$. It can be seen that the development of RV tourism in Ordos is in the early stage of development, but there is a large space for development.
Q: Do you have intention to travel by RV?

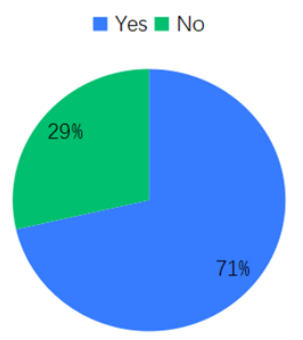

Fig. 5. RV travel intention.

\section{Development countermeasures of RV campsites based on tourism expectation theory}

\subsection{Site selection of RV campsites mainly relies on scenery and transportation}

At present, domestic RV camps are mainly divided into scenic spot dependent, traffic dependent, environmental dependent, project dependent. According to the results of the questionnaire survey, it can be seen that the two factors of scenic spot dependence and transportation dependence are the two most important considerations for the site selection of RV travel camp.The site selection of the camp should be in a place with beautiful environment, close to the scenic spot, and not too far away from the urban area. For example, the desert and grassland around the city of Ordos are good places for site selection.

\subsection{Real Internet publicity mode}

A good publicity can attract customers to the greatest extent. However, false publicity makes customers' expectations higher. If the actual situation cannot be satisfied, it will produce a low evaluation.(1) Pay attention to the authenticity of the propaganda in the publicity, this article captures the public comments on review of the top ten RV camp in Inner Mongolia, according to the evaluation of RV camp, visitors to camp request is not high, but the basic clean, convenient transportation and beautiful environment, good service attitude, etc. As the main content of the critique, propaganda campaigns can be mainly from the above content, and for view or the traffic to promote vigorously highlighting features;(2) With the help of the Internet, the publicity effect is better. We should not only pay attention to the online publication of publicity information, but also pay attention to the comments of consumers on the review websites. Good comments will bring better publicity effect, which is the significance of the valence of expectation theory.

\subsection{Intelligent and diversified RV tourism services}

In terms of food and beverage, Chinese food, special food and buffet are three kinds of catering. Food is the most important thing for people in Inner Mongolia. At the same 
time, Mongolian food, Hetao food and other diversified catering services with local characteristics are more attractive for tourism decision-making.In the camp entertainment projects, sports, recuperation, science and technology and entertainment accounted for the largest proportion, especially the addition of parent-child game projects, through these entertainment projects can achieve the purpose of relaxing body and mind, relieving pressure, getting close to nature and accompanying family members.Invest in emergency protection, such as video of emergency safety demonstration on the front desk. Through intelligent and diversified services to attract consumers, so as to encourage consumers to make the choice of camp in RV tourism decisions.

\subsection{Focus on the development of surrounding tourists and strive to create a good weekend destination for parents and children}

According to statistics, although affected by the epidemic in 2020, the parent-child travel market has recovered considerably and its quality has improved significantly. As well as the results of the questionnaire, it can be seen that short-term, close family travel has become the best choice to enjoy the weekend.According to the surrounding environment, updating ideas, creating unique personality parent-child travel patterns, such as Lu You RV create Kangbashi light sky camp, ovens in snow and ice paradise RV camp, relying on the desert and establish HaoLang camp, ordos Abuhai gully grassland RV camping site, racing car drive sports camp camp, will become the ordos parent-child weekend a good place for entertainment.

\section{Conclusion}

RV travel has become a new trend of travel mode, attracting many people because of its privacy, safety and freedom.Based on expectancy theory, this paper analyzes the RV tourism decision-making influence factors and the bearer of the questionnaire survey on ordos citizens. According to the 217 questionnaires and tourism expectancy theory, this paper puts forward the feasible suggestions on the development of RV camp, in order to promote the development of RV camp and ordos tourism, and promote the development of diversification of ordos tourism.

\section{Acknowledgments}

Thanks to Ordos Institute of Technology for its great support to the research project "Research on Consumer Behavior in RV Camp Based on R ", and thanks to the team members for their efforts in RV tourism research.

\section{References}

1. Chen Y. (2019)The Chinese and foreign rv tourism literature research $[\mathrm{J}]$. Journal of travel survey (second half), 4: 74-77 + 84.

2. Li F, Wang D. (2019)Research on the development of
RV campsites based on visitors' online reviews: A case study of Suzhou Tahu RV campsites [J]. Geography and Geo-Information Science, 35(02):135-140.

3. DING H. (2018)Current Situation, Problems and Future of Self-driving RV Camps in China [J]. China Highway, 18:76-79.

4. "2018 China RV Camping Market Prospect Research Report" released by China Commercial Industry Research Institute.

5. Yang D. (2016)Investigation and Analysis of Consumer Behavior in RV Camp [D]. Hangzhou Normal University,2016.

6. Zhang Z, Zhi G, Ke K, Li B. (2020)Analysis on customer demand of domestic RV tourist camp [J]. Modern Enterprise, 04:127-128.

7. Ma R, Wang R, Zuo X.(2013) Principles of management [M]. People's Posts and Telecommunications Press:25-122.

8. Yue X. (2014)The influence of tourism expectation theory on sports tourism consumption motivation $[\mathrm{J}]$. Journal of $\mathrm{Xi}$ 'an University of Physical Education,31(06):679-682.

9. Li L.(2017) The status quo and thinking of operators' big data application in tourism industry $[\mathrm{J}]$. Tourism Tribune,32(09):9-11.

10. Wang H, Zhou W. (2017)Analysis of ice and snow sports tourism consumption behavior based on expectation theory $[\mathrm{J}]$. Journal of Hubei Second Normal University,34(08):79-84.

11. Wu M.(2015)Research on English Interpretation Strategies of Red Tourism Based on Tourist Expectation Theory [J]. Journal of Huzhou Normal University,37(02):84-87. 